\title{
Current Strategies to Identify Patients That Will Benefit from TACE Treatment and Future Directions a Practical Step-by-Step Guide
}

\author{
Lukas Müller ${ }^{\text {,** }}$ \\ Fabian Stoehr ${ }^{l, *}$ \\ Aline Mähringer-Kunz' \\ Felix Hahn (D) \\ Arndt Weinmann (iD ${ }^{2}$ \\ Roman Kloeckner (ID) \\ 'Department of Diagnostic and \\ Interventional Radiology, University \\ Medical Centre of the Johannes \\ Gutenberg-University Mainz, Mainz, \\ Germany; ${ }^{2}$ Department of Internal \\ Medicine I, University Medical Center of \\ the Johannes Gutenberg University \\ Mainz, Mainz, Germany
}

*These authors contributed equally to this work.
Correspondence: Roman Kloeckner Department of Diagnostic and Interventional Radiology, University Medical Center of the Johannes Gutenberg-University Mainz, Langenbeckst. I, Mainz, 55।31, Germany Tel +49 6131 17-2019

Email roman.kloeckner@unimedizinmainz.de

\begin{abstract}
Treatment of hepatocellular carcinoma (HCC) depends on the stage of disease. In the Western Hemisphere, the Barcelona Clinic Liver Cancer classification (BCLC) is the preferred staging system. Approximately one-third of patients initially present with intermediate-stage disease. For these patients, transarterial chemoembolization (TACE) is the treatment of choice. However, the intermediate-stage comprises a heterogeneous subgroup of patients with considerable differences in tumor burden and liver function. In addition, differences in individual factors that are not captured by the BCLC framework, such as the tumor growth pattern, degree of hypervascularity, and vascular supply, complicate further evaluation of these patients. Due to these differences, not all patients benefit equally from TACE. Several tools and scoring systems have been devised to provide decision-making support. All of these have shown promising initial results but failed external evaluation and have not been translated to the clinic. Nevertheless, criteria for objectifying treatment decisions in daily clinical practice are needed in all stages of disease. Therefore, this review provides a concise practical step-by-step guide on current strategies for patient selection and decisionmaking, with a focus on TACE, to critically evaluate the existing decision-support tools and provide a summary of the latest updates in the field.
\end{abstract}

Keywords: hepatocellular carcinoma, transarterial chemoembolization, survival prediction, treatment decision support, practical step-by-step guide

\section{Introduction}

Hepatocellular carcinoma (HCC) is one of the most common and deadliest cancers worldwide. $^{1,2}$ In the Western Hemisphere, the Barcelona Clinic Liver Cancer classification (BCLC) is the preferred staging system. ${ }^{1,3}$ The system is based on tumor stage, liver function, and the patient's performance status, classifying patients from (very) early (BCLC 0 and A) and intermediate (BCLC B) to advanced and terminal stage (BCLC C \& D). ${ }^{4}$ A treatment recommendation is linked to each stage; transarterial chemoembolization (TACE) is the standard of care for intermediate-stage patients. ${ }^{1,3}$ These recommendations are mainly based on two trials showing significant improvement in median overall survival (OS). ${ }^{5,6}$ However, these trials were conducted in a highly selected patient cohort that does not reflect clinical reality, as the intermediate stage comprises a heterogeneous subgroup of patients with considerable differences in tumor burden and liver function. ${ }^{7}$ To further improve treatment allocation, the BCLC subclassification was developed. ${ }^{7}$ However, it has not been able to offer significant benefit for patient stratification. ${ }^{8,9}$ Nevertheless, the rationale behind further subclassification of the intermediate stage emphasizes the fact that not 
every patient benefits equally from TACE and that several patients might profit from a switch to systemic therapy. Thus, selecting the "right" patient remains crucial. To address this issue, several attempts have been made to provide solutions and tools to support decision-making and patient selection. Thus, the aim of this review is to provide a concise, up-to-date overview of the available stratification strategies and to provide a practical step-bystep guide on how to select the optimal TACE candidate.

\section{Treatment Decision Before and During TACE: What are the Most Critical Time Points?}

Treatment decisions apply during the entire course of disease (Figure 1). In this document, we strive to:

a) identify the perfect candidate to start initial TACE treatment,

b) try to support decision-making during the course of TACE treatment and finally to

c) provide guidance on when to stop TACE.

\section{Start of TACE Treatment: Which Patients are Optimal Candidates for TACE?}

In a typical intermediate-stage patient cohort, median OS is approximately 2.5 years. ${ }^{10}$ Survival rates can increase to up to 4 years if the inclusion criteria for TACE are followed more strictly. ${ }^{11}$ Such discrepancies underline the need to select the most suitable patients for TACE. However, despite the suggestions of Western guidelines, in clinical reality, the decision of whether to start TACE treatment remains a complex decision with a multitude of possible factors influencing the process.

During the last decade, several predictive factors have been identified. Image-derived tumor features allow important insights. First and foremost, the important features tumor size and number of lesions correlate with patient outcome. ${ }^{1,6,11-14}$ Furthermore, a larger tumor size correlates with an inferior response to TACE and a higher risk of postembolization syndrome. ${ }^{14-18}$ The post-embolization syndrome describes a combination of symptoms including fever, nausea, vomiting and pain in the right upper quadrant, which occurs in up to $80 \%$ of the patients. ${ }^{19-21}$ It is the most common adverse event after TACE and the major reason for an acute inpatient management leading to a prolonged length of stay. ${ }^{22}$ A commonly used cut-off for tumor size is $5 \mathrm{~cm} .{ }^{18,23}$ In particular, the up-to-7 criteria, a combination of tumor size and number of lesions, originally designed to assess the suitability for liver transplantation, have shown good correlation with the median OS after TACE. ${ }^{24}$
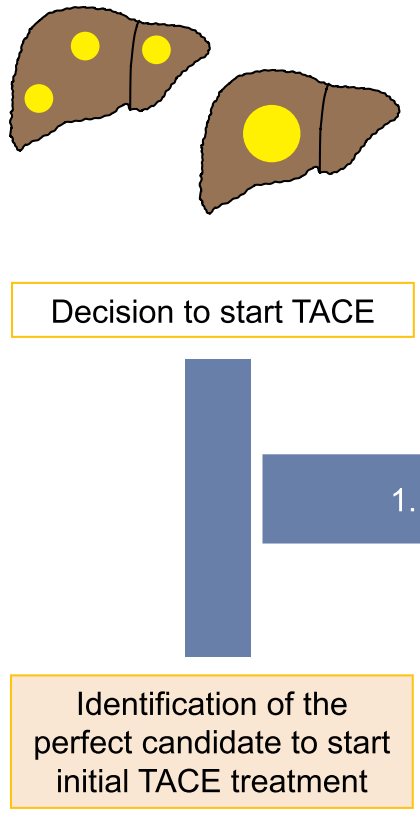

Identification of patients who are likely to benefit from TACE continuation

Decision whether to continue TACE or switch to systemic treatment

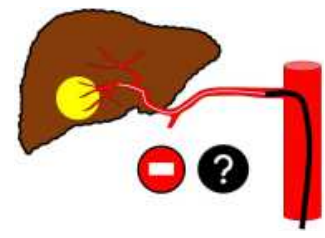

Decision whether to stop TACE
1. TACE Session

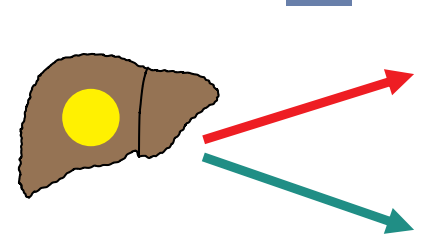

Further TACE Sessions

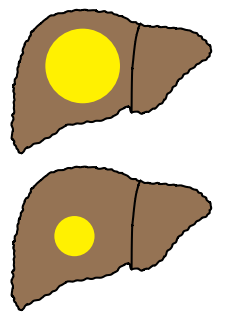

Identification of the right time to stop TACE and evaluate further treatment options

Figure I Overview of decisions applying to TACE treatment. 
Moreover, imaging enables the identification of features associated with a more aggressive tumor biology. These factors, to a great extent, influence the feasibility and success of TACE, though they are not included in the BCLC staging system. One of these factors is the degree of vascularity: hypervascular tumors are more responsive to TACE treatment, easier to identify during the treatment, and have a favorable outcome. ${ }^{13,14,25}$ Another important issue is the arterial anatomy: Few tumor-feeding vessels and favorable anatomy enable superselective embolization. In contrast, unfavorable anatomy, such as extensive parasitic arterial tumor-feeders, may complicate a superselective procedure, eventually resulting in ineffective TACE. A superselective procedure is important in order to maximize tumor necrosis while minimizing TACE-associated side effects to the healthy liver parenchyma. ${ }^{18}$ Figure 2 displays an example for unfavorable and favorable.

An important indicator of tumor aggressiveness is the growth pattern. Infiltrative tumor growth is associated with an impaired response and impaired median OS compared to patients with nodular tumor growth and a clear boundary to the surrounding liver parenchyma. ${ }^{26-28}$

Imaging enables the detection of ascites and hepatomegaly, which are associated with impaired survival. ${ }^{29-32}$ Furthermore, the size of the spleen can be assessed easily, which functions as a surrogate marker of portal hypertension and is, itself, an additional negative predictor of the median OS. ${ }^{33}$

Laboratory parameters representing liver function and the HCC-related tumor marker alpha-fetoprotein (AFP) are the second component of the patient evaluation for TACE because they are easy to capture during clinical routine. ${ }^{17,34-42}$ Historically, the Child-Pugh Score (CPS) was the standard tool for stratification of cirrhotic patients. ${ }^{1}$ However, the CPS has two major restrictions in the evaluation of HCC patients: Firstly, it does not fully capture deterioration due to temporary events within the progression of cirrhosis. Secondly, the CPS includes parameters that depend on subjective assessment, which may hamper its validity. ${ }^{1}$ Therefore, new stratification tools may be needed for the evaluation of HCC patients. One of these tools is the combination of albumin and bilirubin as the albumin-bilirubin score (ALBI), which is an easy-to-calculate indicator of the estimated hepatic reserve and has been shown to be highly predictive. $^{43,44}$ Albumin is an important marker of liver function and has been repeatedly identified as a strong prognostic factor. ${ }^{45,46}$ High bilirubin levels are associated with a higher risk of post-procedural liver decompensation and, therefore, are a negative prognostic factor for median OS. ${ }^{21,30}$ Of the other liver synthesis parameters, low cholinesterase, high INR, and low platelet count may complement the ALBI score in the decision-making process. ${ }^{1,47}$

The role of other factors, such as the $\mathrm{C}$-reactive protein (CRP) level prior to the first TACE treatment remain unclear. Though several publications have stated that CRP only represents a surrogate parameter for systemic inflammatory response syndrome and tumor aggressiveness, ${ }^{48,49}$ others have stated that high CRP levels are related to poorly differentiated tumors. ${ }^{50}$ While Kinoshita et al found CRP to be an independent prognostic factor associated with a poor prognosis regardless of the
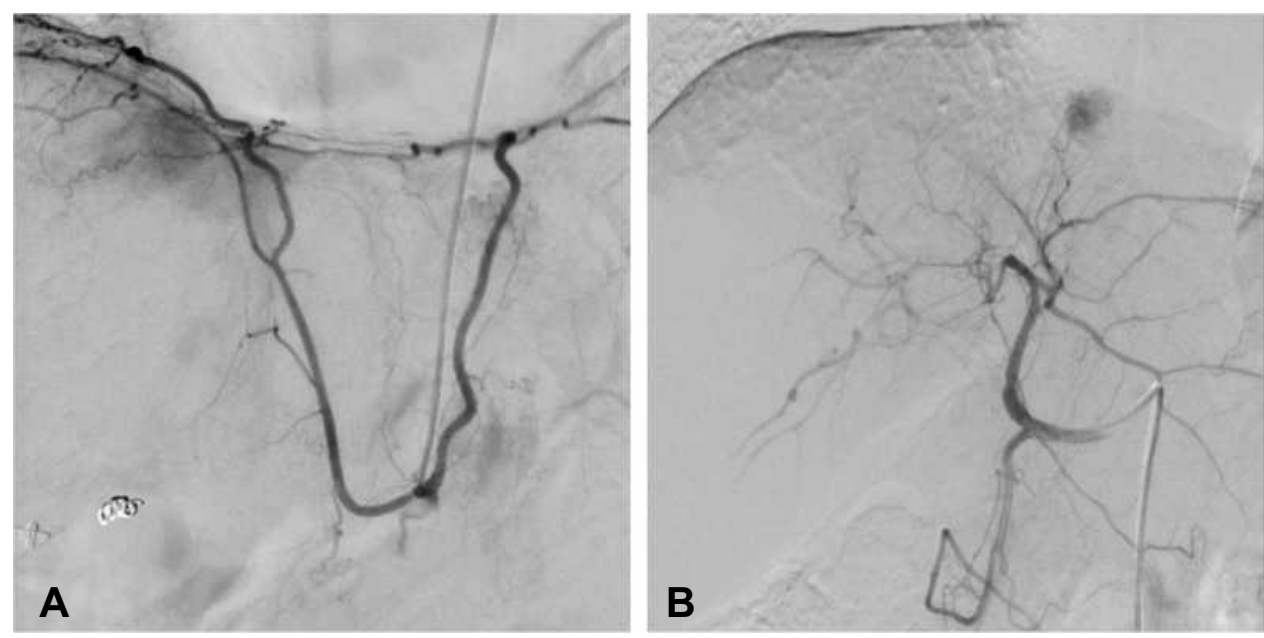

Figure 2 The left image (A) shows an example of a patient with a parasitic tumor supply: in this case the tumor is supplied by a strong right inferior phrenic artery, which is the most common variant of parasitic tumor supply. The right image (B) provides an example of a favorable vascular supply for TACE: a small branch of the segment two artery enables a superselective embolization. 
BCLC status and treatment modality, ${ }^{51}$ for TACE treatment the results are divergent. ${ }^{34,42}$

Even though current Western guidelines downgraded the value of AFP for screening and diagnosis, ${ }^{1,3}$ there is evidence that static, and especially dynamic, AFP values (in the form of changes before and during treatment) are related to the median OS. ${ }^{45,46,52-54}$ On a molecular basis, AFP plays a role in tumor angiogenesis and may affect tumor cell proliferation and tissue growth. ${ }^{55}$ For patients treated with TACE, AFP has been an independent predictor of the median OS in several studies. ${ }^{55-57}$ However, discussion of optimal cutoffs is ongoing and the current evidence heterogeneous. The AFP dynamics may be more appropriate and could function as an indicator of tumor aggressiveness. ${ }^{52}$ Recently, results from the REACH 2 trial on ramucirumab as a systemic treatment in patients with advanced HCC showed that AFP levels may have a stronger influence than expected on the therapeutic response. ${ }^{58}$ Further investigations are needed to evaluate the role of AFP in the context of TACE treatment.

Figure 3 summarizes the factors as patient-, tumor-, and treatment-associated features to be considered before starting TACE.

\section{Choice of the Best Technique}

During HCC development and progression, the tumor tissue shows intense neo-angiogenesis leading to a strong arterial tumor supply. ${ }^{1}$ With the embolization of the supplying arterial vessels, the induction of ischemia is intended. This selective ischemia of the tumor tissue leads to a shutdown of cell metabolism and causes a growing rate of cell death. This process synergistically strengthens the cytotoxic effect of the applied chemotherapeutic agents with the ultimate goal of a complete tumor necrosis. ${ }^{1}$ The surrounding liver parenchyma is protected from relevant ischemic cell death as it is physiologically receiving most of its blood supply by the portal venous system.

Two TACE techniques are mainly used in clinical routine: conventional TACE (cTACE) and TACE with drugeluting beads (DEB-TACE). In 2002, cTACE was first shown to improve OS against best supportive care (28.6 months vs 17.9 months). ${ }^{5}$ The treatment was based on the injection of a chemotherapy emulsion (ie, doxorubicin, epirubicin, idarubicin, mitomycin C, or cisplatin) and lipiodol, followed by an embolizing agent in order to enhance the ischemic effect (ie, gelatin sponge, polyvinyl alcohol particles, or microspheres). In 2006, drug-eluting beads were introduced in order to improve the therapeutic effect while reducing side effects due to slower release of the chemotherapeutic agents. ${ }^{59}$ However, the first head-to-head trial did not yield significant superiority to cTACE regarding the median OS. ${ }^{60}$ Following these initial results, several randomized trials attempted to prove the superiority of DEB-TACE over cTACE. However, until today, no significant difference has been shown between cTACE and DEB-TACE regarding tumor response or survival. ${ }^{10,61}$ The only findings were less post-procedural pain and fewer chemotherapy-associated systemic side effects after DEB-TACE. ${ }^{10,60}$

Regarding the optimal chemotherapeutic agent, all drugs performed relatively similar in randomized trials. ${ }^{62}$ Therefore, no clear recommendation towards one specific chemotherapeutic agent can be made. Another important technical aspect that has to be considered during TACE treatment is the optimal embolization endpoint. Evidence on the topic is low and study results contrary: While Jin et al showed that a residual antegrade blood flow after TACE increases the median OS, Habbel et al found no direct relation between the subjective angiographic chemoembolization endpoint and the median OS. ${ }^{63,64}$ Thus, it remains unclear whether an intermediate substasis or a higher, stasis embolization endpoint is favourable.

As mentioned above, the recommendation of TACE for patients in intermediate stage is mainly based on two trials showing significant improvement in median OS. ${ }^{5,6}$ The efficacy of TACE is further supported by the results of several meta-analysis. ${ }^{65,66}$ Against this robust evidence, the Cochrane investigators questioned the role of TACE on survival in 2011 as their meta-analysis yielded no benefit for TACE compared to best supportive care. ${ }^{67}$ They argue that the original studies were conducted on a highly selected patient cohort. However, the review has several methodical weaknesses and its results never entered clinical reality.

Recently, several modifications of the conventional TACE technique have been proposed. One is the balloonoccluded TACE (B-TACE), which is defined as the infusion of emulsion of chemotherapeutic agents with lipiodol followed by gelatin particles under the occlusion of feeding arteries by a microballoon catheter. ${ }^{68}$

First evaluation studies concluded a superiority of B-TACE compared to conventional TACE. ${ }^{69-71}$ However, studies were conducted retrospectively on relatively small sample sizes, thus, randomized controlled trials are mandatory. Another modification of conventional TACE is the combination with a lipiodol-ethanol mixture, which showed promising results in initial evaluation. ${ }^{72,73}$ Based on the 


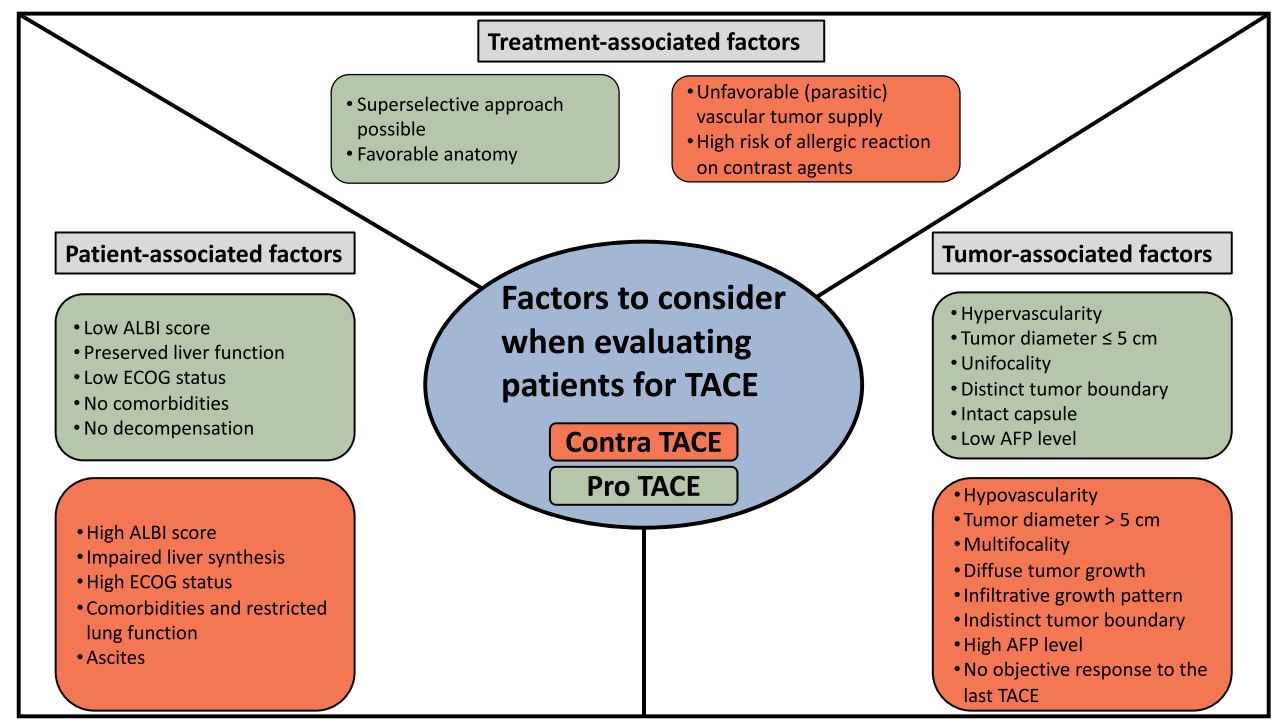

Figure 3 Overview of prognostic factors to consider when evaluating patients for TACE (factors pro TACE = green, factors contra TACE $=$ red).

causing of endothelial damage and thrombosis of the arterial feeder vessels, the lipiodol and ethanol mixture may enhance the embolization effect of TACE. ${ }^{74}$ However, currently evidence is limited on these techniques as well-designed randomized controlled trials are missing.

As mentioned above, with the use of selective arterial embolization a tumor necrosis is intended. However, the induced hypoxia increases the upregulation of vascular endothelial growth factor and pplatelet-derivedgrowth factor, which leads to an increase of re-vascularization. ${ }^{75-77}$ Thus, the adjuvant application of antiangiogenic systemic therapy may further reduce tumor volume and arterial tumor supply. One possible option is the antiangiogenic multikinase inhibitor sorafenib, which is currently a recommended treatment option for HCC patients with unresectable HCC in BCLC stage C. However, the combination of TACE with sorafenib and other molecular targeted agents so far yielded no survival benefits. ${ }^{78-83}$ While the results of the TACTICS trial report an improved progression-free survival for the combination, the recently published final data showed no improvement in median OS. ${ }^{84,85}$ Thus, the combination of TACE and targeted agents might be a valuable treatment option in individual scenarios but cannot be generalized to all patients.

\section{During the Course of Treatment: How Often and When Should TACE Be Repeated?}

After the initial TACE procedure, re-evaluation of each individual patient is necessary. The treatment response in particular is an indispensable factor to further guidance, as it functions as a strong predictor of median OS and may be seen as a metaparameter. As tumor necrosis is not necessarily accompanied by immediate reduction of the tumor size, ${ }^{86}$ conventional RECIST criteria, which are based on the maximum tumor diameter, may tend to underestimate the tumor response. ${ }^{87,88}$ As HCCs have predominantly arterial (hyper-) vascularization, modified RECIST (mRECIST) criteria measuring the sum of the longest diameter of contrast-enhancing tissue have been developed and are the recommended assessment of response by the Western guidelines. ${ }^{1,89,90}$ As in the conventional criteria, the patient's response to TACE can be classified as a complete response (CR), partial response (PR), stable disease (SD), or progressive disease (PD). Table 1 displays a detailed description of the mRECIST criteria in their current form.

Figure 4 provides an example for PR and CR.

These different stages of response create various scenarios:

The first scenario is patients with residual vital tumor and PR (or at least SD) after the initial TACE session. For these patients, there is no standardized re-treatment policy. ${ }^{86}$ Regarding an optimal re-treatment schedule, there are no clear evidence as to whether repeated TACE after predefined time intervals or repetition in case of progression is better. Based on the positive experience in the initial trials, common practice is initial treatment with two TACE sessions within 1-2 months because this may lead to better response rates. ${ }^{91}$ Afterwards, regular intervals may lead to improved monitoring of the case, but an aggressive schedule may also 
increase the risk of liver failure. ${ }^{91,92}$ Either way, liver function and performance status have to be monitored closely in order to avoid "overtreatment". 93 Continuous re-evaluation of each patient by an interdisciplinary tumor board including experienced hepatobiliary surgeons, hepatologists, interventional radiologists, and oncologists is of utmost importance to not miss the optimal timing for a switch to systemic treatment when subsequent therapy is still possible. Therefore, response assessment is indispensable prior to each TACE treatment. To this end, cross-sectional imaging (CT/MRI) should be performed immediately before TACE. This allows, in addition to the response assessment, the recording of important factors representing tumor biology as mentioned above. In cTACE, the extent of lipiodol accumulation on CT images is associated with the extent of tumor necrosis. ${ }^{94,95}$ However, MRI may be helpful in assessing residual viable tumor tissue due to the "blooming effect" of the lipiodol staining in $\mathrm{CT}^{96}$ After DEB-TACE, CT and MRI can be used interchangeably. ${ }^{96}$

After successful initial TACE with CR, recurrence can appear as either re-vascularization of the treated tumor ${ }^{1}$ or in the form of new tumor lesions. For both scenarios, repetition of TACE may be necessary to secure therapeutic success. However, to ensure that a particular patient is still a good TACE candidate, discussion by the interdisciplinary tumor board is of greatest importance, too.
Table I Modified RECIST Criteria ${ }^{1,89,90}$

\begin{tabular}{|l|l|}
\hline $\begin{array}{l}\text { Classification of } \\
\text { Response }\end{array}$ & Criteria Definition \\
\hline Complete response (CR) & $\begin{array}{l}\text { No intratumoral arterial enhancement in } \\
\text { all target lesions }\end{array}$ \\
\hline Partial response (PR) & $\begin{array}{l}\geq 30 \% \text { reduction of the sum of diameters } \\
\text { of viable (enhancement in the arterial } \\
\text { phase) targets lesions }\end{array}$ \\
\hline Stable disease (SD) & $\begin{array}{l}\text { Feature classifiable as neither partial } \\
\text { response nor progressive disease }\end{array}$ \\
\hline Progressive disease (PD) & $\begin{array}{l}\geq 20 \% \text { increase in the sum of the } \\
\text { diameters of viable target lesions }\end{array}$ \\
\hline
\end{tabular}

TACE should be stopped immediately in cases of initial unresponsiveness or "untreatable progress", defined as massive liver involvement, extrahepatic spread, vascular invasion, impaired liver function, or worsening performance status. ${ }^{86,97}$

Figure 5 summarizes the patient scenarios for reevaluation during TACE treatment.

\section{Patients No Longer Benefiting from TACE}

It is crucial to identify patients who are not benefitting from TACE as soon as possible, as these patients could still benefit from systemic therapy as long as the tumor burden and liver

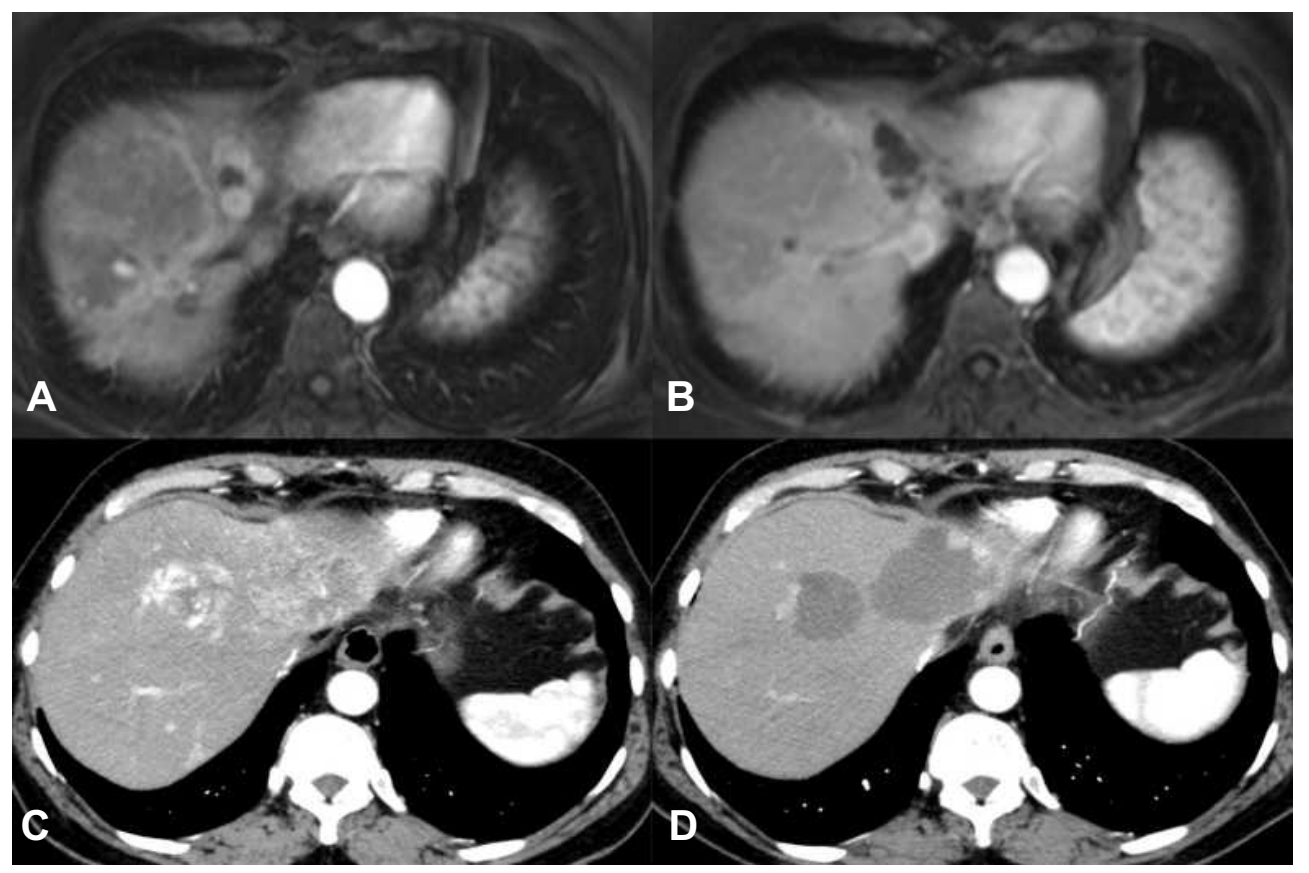

Figure 4 The upper row shows an example of complete response according to the modified RECIST criteria (A and $\mathbf{B})$. The lower row displays an example for partial response (C and $\mathbf{D})$ with a peripheral residual hypervascularization of the tumor nodules. 
function allow for it. ${ }^{98}$ In clinical routine, this "point of no return" is difficult to determine. As mentioned above, continuous and standardized imaging in combination with repetitive laboratory assessment, including liver function parameters and AFP, forms the basis for accurately timing the switch to systemic treatment after refractory TACE. An inappropriately high number of TACE sessions delays the switch to systemic therapy and may, in some cases, completely hinder the treatment switch due to the deterioration of liver function. ${ }^{98-102}$ Both situations may be associated with impaired survival.

High tumor burden, multifocality, impaired liver function, early recurrence, incomplete necrosis, massive progression under TACE, and the occurrence of extrahepatic spread and/or vascular invasion should trigger the cessation of TACE treatment and re-evaluation by an interdisciplinary tumor board. ${ }^{98}$ Furthermore, unbearable side effects of TACE, such as severe forms of post-embolization syndrome, should also lead to re-evaluation, as they may strongly influence the patient's quality of life. These patients may also benefit from a switch to systemic treatment. However, extensive discussion with the patient of the possible benefits and disadvantages of the switch is inevitable.

\section{Alternative Treatment in Intermediate Stage}

For patients with a limited tumor burden, namely oligonodular disease with a tumor diameter $<5 \mathrm{~cm}$, liver resection has to be considered as a treatment option. ${ }^{103}$ However, the most common limitation for curative resection beyond early stages is the impaired liver function, which has repeatedly been identified as an independent predictor for a reduced median OS. ${ }^{104}$ In this case, thermal ablation offers another feasible curative treatment option. ${ }^{1}$ If the tumor size exceeds $5 \mathrm{~cm}$, thermal ablation and TACE can be combined allowing for ablations up to $6 \mathrm{~cm}$ with good response rates. ${ }^{105-108}$ For patients with localized tumor growth confined to one or two liver segments radiation segmentectomy, which is defined as a highly selective radioembolization limited to $\leq 2$ hepatic segments, is a curative treatment option; especially in case of impossible thermal application and curative resection due to a challenging tumor location. ${ }^{109,110}$ One currently intensively investigated therapy option for patients with HCC is the external beam radiation therapy. Through advances in radiation technique, precise stereotactic targeting of the tumor tissue is possible, while sparing out the surrounding liver parenchyma (SBRT). The few available studies for intermediate stage proved that SBRT might be an option in combination with TACE or thereafter. ${ }^{111,112}$ A head-tohead comparison of both techniques is currently being assessed in the TRENDY trial (NCT02470533).

Regarding systemic treatment as first-line option for the intermediate stage, Kudo et al recently promoted Lenvatinib as a superior option for patients with a high tumor burden. ${ }^{113}$ However, due to the relatively small sample size and the retrospective design, the results should be interpreted as an initial proof-of-concept study and cannot replace prospective randomized trials. A little more is known on systemic treatment following on TACE refractoriness. Several retrospective studies proved that a switch to systemic therapy in case of TACE refractoriness improved median OS. ${ }^{101,114}$ However, as mentioned above, to identify the "right" point for treatment

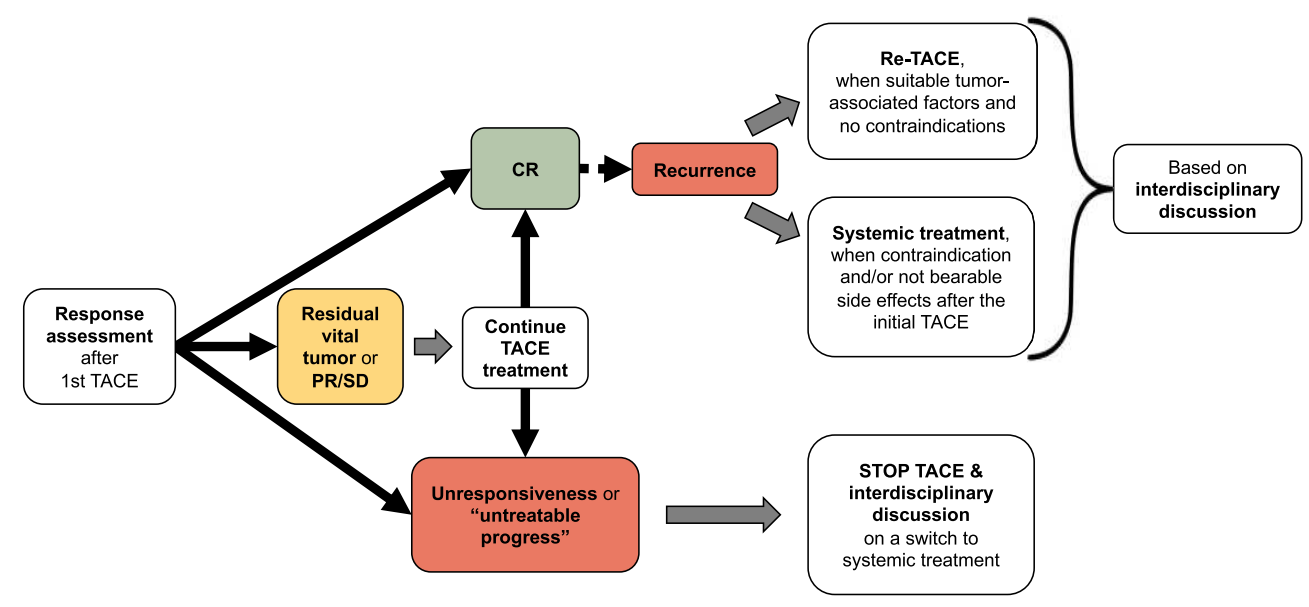

Figure 5 Flowchart of the re-evaluation criteria and decision-making during TACE treatment. 
transition remains crucial. One prospective trial currently investigating the role of sorafenib following TACE is the OPTIMIS trial (NCT01933945), which has a special focus on the patient status when sorafenib treatment is started. Further prospective trials on various systemic agents after TACE refractoriness are urgently needed.

\section{Scoring Systems: Appropriate Support for Decision-Making Before and During TACE Treatment?}

To specifically address the initial question as to whether to start TACE, the STATE (Selection for TrAnsarterial chemoembolization TrEatment) score and HAP (Hepatoma Arterial-embolization Prognostic) score and its modifications (mHAP-II and -III) have been devised. $^{34,45,53,54}$ The STATE score consists of serum albumin, tumor burden (up-to-7 criteria), and CRP level. ${ }^{34}$ Patients with a lower STATE score had a significantly impaired median OS (5.3 months vs 19.5 months). Therefore, the authors concluded that patients with a low STATE score should not be treated with TACE. The score can be applied to both TACE types.

The HAP score includes serum levels of albumin, bilirubin, and AFP and the tumor size and categorizes patients into four subgroups. ${ }^{53}$ To improve the predictive ability of the score, two adaptations have been made. In the mHAP-II score, adding the number of lesions as a factor improved the stratification. ${ }^{54}$ The mHAP-III is also adjusted by taking into aaccountspecificweighting factors, creating an individual prediction of prognosis (online calculator http://www.livercan cer.eu/mhap3.html). ${ }^{45}$

Though both the STATE and HAP scoring systems had promising stratification results, external validation by other groups showed only a moderate ability to predict each patient's individual prognosis. ${ }^{42,46}$ Mähringer-Kunz et al confirmed the ability of the STATE score to stratify patients regarding the median OS. ${ }^{42}$ However, their results indicate remarkable overlap in the distribution of survival. Following their results, the authors do not recommend basing clinical decisions on the STATE score alone. The same is true for the HAP score and its modifications; though all models provide good stratification with regard to the median OS, the model accuracy was only moderate in external validation, not allowing for clear-cut clinical decisions. ${ }^{45,46,54}$

Recently, another attempt has been made to identify patients who benefit from TACE by using the "six-and- twelve" score. ${ }^{115}$ As an easy-to-use tool, this score stratifies ideal TACE candidates by the sum of tumor size and number of lesions. However, the first external validation results yielded only moderate predictive ability. ${ }^{116,117}$ Very recently, a complex linear predictor has been proposed by Han et al: The Pre-TACE-Prediction model namely for patient evaluation before the initial TACE. Despite the serological parameters (albumin, bilirubin and AFP) and imaging parameters (tumor number, tumor size and vascular infiltration), this predictor includes the aetiology behind the liver disease. ${ }^{118}$ Despite promising results in the initial study, the usefulness of this model has to be evaluated in future studies.

Figure 6 provides a detailed overview of all these scores and their parameters.

To answer whether TACE should be continued, additional scoring systems have been based on the response and tolerance to the initial session. ${ }^{9,23,35}$

In 2013, Sieghart et al devised the Assessment for Retreatment with TACE (ART) score based on the aspartate aminotransferase (AST) level, CPS, and radiological response. ${ }^{35}$ The score showed significantly impaired survival for patients in the higher scoring group. Furthermore, a high ART score was significantly associated with a greater number of major adverse events after the second TACE treatment. Adhoute et al followed similar methodology when creating their ABCR (AFP, BCLC, Child-Pugh, and Radiological Response) score. ${ }^{9}$ A third scoring system was introduced in 2016: the SNACOR score includes tumor size, tumor number, baseline alphafetoprotein level, CPS, and objective radiological response. $^{23}$ Recently, Han et al proposed Post-TACEPrediction, which is a linear predictor for patient stratification after the initial TACE treatment. ${ }^{118}$ The predictor is based on the serological parameters AFP and bilirubin and the imaging parameter tumor size, number of lesions and radiological response, which are summarized in a complex formula. Similar to the Pre-TACE-Prediction model by the same group mentioned above, the usefulness of this model has to be evaluated in future studies.

Figure 7 provides a detailed overview of all of these scores and their included parameters.

Similar to the results for the above-mentioned scores at the start of TACE, all available scoring systems for the continuation of TACE failed in independent external validation, with only moderate accuracy in individual prognostic prediction. ${ }^{17,36-41,119}$ Validation of the ART and ABCR scores with our own data showed that both scoring systems are able to stratify patients according to their median OS. ${ }^{41}$ 
The ABCR score was slightly more accurate for our patient cohort. However, both scores yielded only moderate value in individual prognostic prediction. In addition, we evaluated the SNACOR score, which also had the ability to significantly stratify patients in terms of the median OS but failed in terms of individual prognostic prediction. ${ }^{119}$

In accordance with all of these rather disappointing results, the EASL guidelines panel considers the use of the scoring systems controversial and recommends that TACE should not be repeated when substantial necrosis is not achieved after two rounds of treatment or when follow-up treatment fails to induce marked necrosis at sites that have progressed after an initial tumor response. ${ }^{1}$

The latter is supported by Georgiades et al, who showed that at least two TACE procedures have to be performed before it is possible to make a decision as to whether to continue with TACE. ${ }^{91}$

In summary, all of the mentioned scores may estimate prognosis, but they cannot support clear-cut clinical decisions. Thus, it is necessary to discuss the indication for each TACE treatment as an interdisciplinary tumor board including experienced hepatobiliary surgeons,
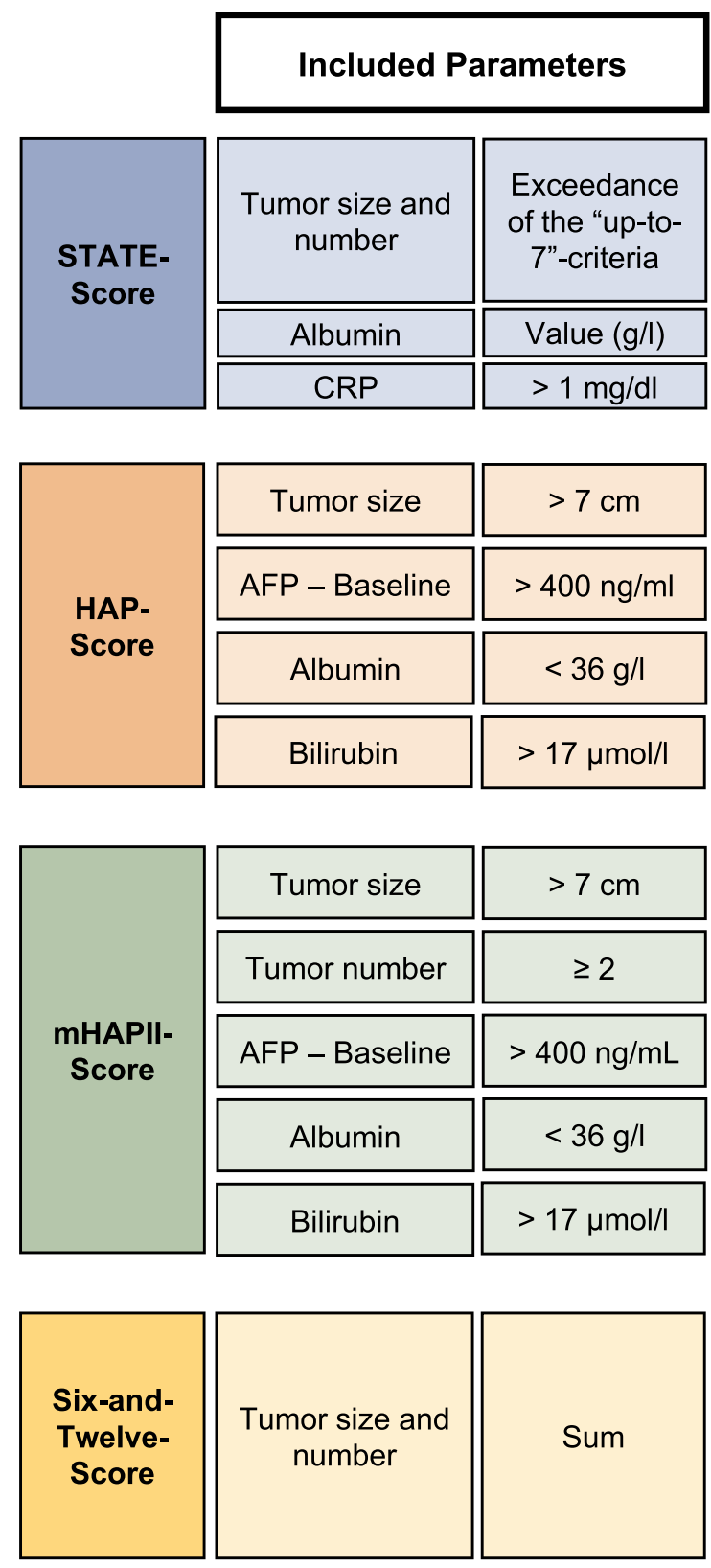
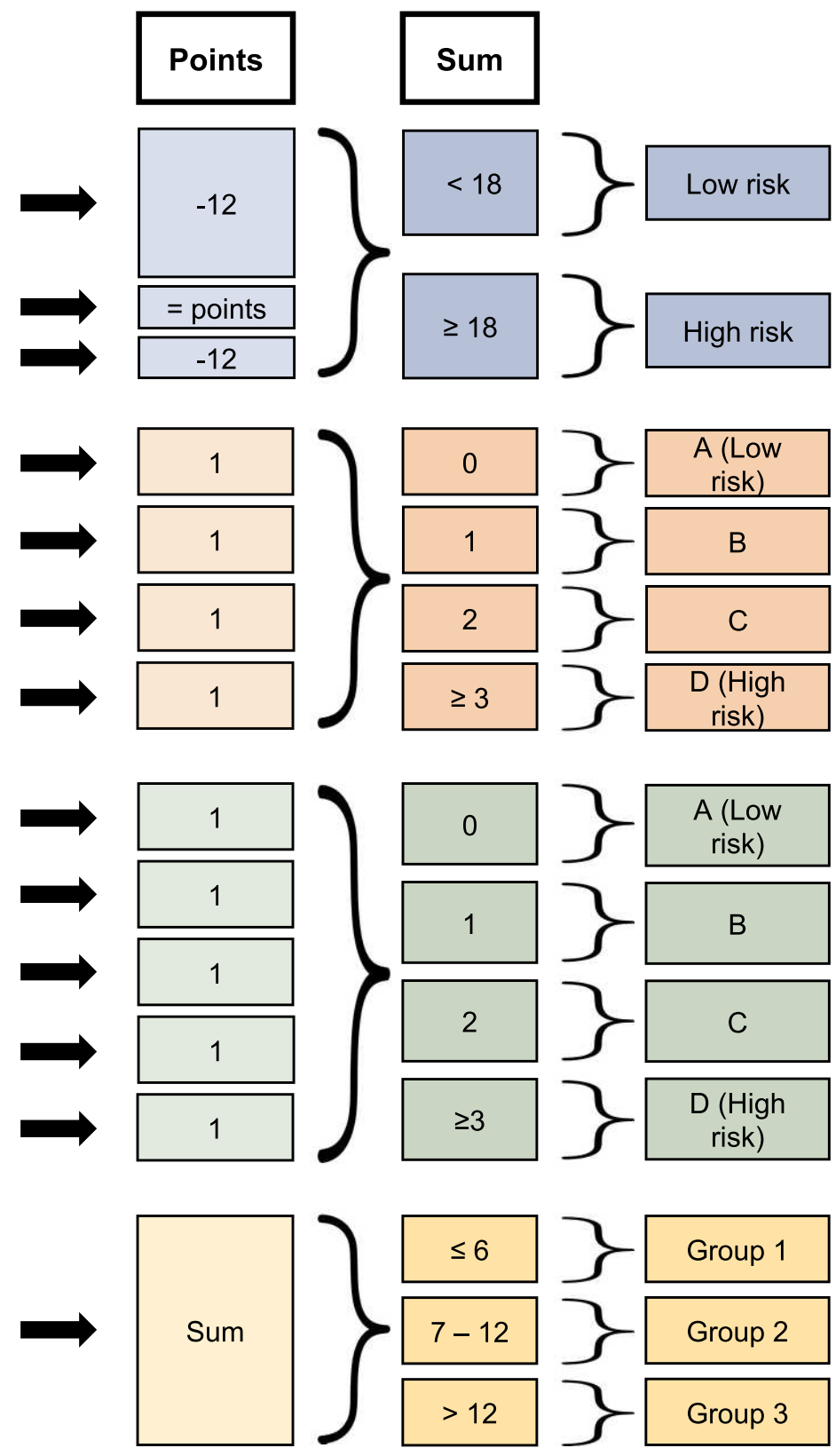

Figure 6 Overview of the scoring systems applied before TACE treatment. 
hepatologists, interventional radiologists, and oncologists. In particular, the extent of the hepatic tumor, liver function, and patient performance status have to be considered. Finally, the patient's opinion should be an integral part of the decision-making process. In particular, the pros and cons of TACE treatment and the influence on prognosis should play an important role in decision making.

\section{Current Scoring Systems: Why Do They Tend to Fail/Underperform?}

A possible reason for the disheartening validation results for the scoring systems may be that the vast majority of patients with HCC suffer from concomitant liver cirrhosis, which complicates prediction. Even though several of the scores try to consider both aspects, the use of only 3-5 parameters may be an inappropriate simplification of a much more complex clinical reality.

All of the previously described systems were created based on more or less the same mathematical principles: The coefficient factors of significant parameters in a multivariate regression analysis were adjusted weighting factors based on the datasets from a well-selected cohort. Therefore, overfitting may be a methodological problem related to that approach. Overfitting describes "a phenomenon that occurs when a model maximizes its performance on some sets of data, but its predictive performance cannot be confirmed elsewhere, due to random fluctuations in patient characteristics that occur in different clinical and demographic backgrounds". ${ }^{120}$ Most of the scores were created at single institutions, which may have aggravated the issue of overfitting. In addition, most of the studies are based on only a moderate sample size.

\section{Novel Artificial Intelligence-Based Approaches}

To overcome these limitations, several attempts have been made using artificial intelligence (AI) in the context of TACE treatment in patients with HCC. ${ }^{121-124}$ These attempts can be divided into two groups. Peng et al, Abajian et al, and Liu et al focused on training AI-based systems that can estimate the response to TACE treatment prior to the first session. Peng et al used CT images for pattern recognition. ${ }^{122}$ This approach had promising accuracy for both training and validation. To assess tumor response after TACE, Abajian et al constructed a model based on two MRI features of the tumor and three clinical parameters. ${ }^{121}$ Though the accuracy of their system was slightly lower, this attempt emphasized the capability of AI-based solutions. Recently, Liu et al proved the feasibility of a deep learning-based radiomics model using contrast-enhanced ultrasound cines for survival prediction. ${ }^{124}$ Mähringer-Kunz et al recently reported their results on another auspicious approach: the aim was to train an AI-based network to predict the 1-year survival. ${ }^{123}$ To achieve high accuracy in their prediction, they included 46 parameters, including tumor-related features such as tumor size, number of lesions, and tumor growth pattern, parameters for the assessment of the liver function, risk factors for the development of HCC, and novel meta-parameters, such as the skeletal muscle index. Their novel approach yielded good results in the training and validation cohorts with areas under the ROC curve of 0.77 and 0.83 , respectively. This approach outperformed the ART, ABCR, and SNACOR scores in predicting 1-year survival.

The benefit of all of these AI-based systems is their dynamic learning process; with more available and complete datasets from different institutions, the accuracy of these systems will likely further improve. Nevertheless, the suggested systems have to prove their accuracy in external, multicenter evaluations. Furthermore, how great the added benefit is in clinical decision-making compared to the established stratification systems remains questionable.

\section{Thinking Outside the Box: When to Perform TACE Outside of BCLC B - The Stage Migration Approach}

Stage migration should be considered in patients for whom the recommended treatment options according to BCLC are not feasible or have failed, including TACE, as well as all other options. ${ }^{1,125}$ Usually, the migration is performed as a lleft-to-right approach - this applies to patients in BCLC stage 0/A who are not suitable for surgery or ablation and may be migrated to TACE. However, a rright-toleft approach is also feasible, particularly for patients in BCLC stage C suffering from adverse effects due to systemic therapy. Naturally, such a stage migration has to be discussed in an interdisciplinary fashion. ${ }^{1,125}$

\section{Thinking Outside the Box: When to Perform TACE Outside of BCLC B - "Bridging" and "Down-Staging" for Liver Transplantation}

Another indication for TACE outside of the BCLC staging system is prior to liver transplantation (LT). ${ }^{1} \mathrm{LT}$ has the 




Figure 7 Overview of the scoring systems applied during TACE treatment.

main advantage that it cures $\mathrm{HCC}$ as well as cirrhosis as the main precancerous disease. However, in the context of LT, there are rules/criteria regarding tumor size and extent that have to be followed very strictly (ie, Milan criteria). ${ }^{126}$ As in most regions, high demand meets limited availability of organs, treatment is mandatory for patients while on the waiting list. ${ }^{126}$ TACE is the most common treatment for this "bridging" in order to keep the tumor within the size criteria. ${ }^{1}$ Furthermore, the tumor response to TACE can be helpful in assessing patients' personal tumor biology prior to LT. ${ }^{127}$ Therefore, the response to "bridging-TACE" may be seen as an independent selection criterion. ${ }^{128}$

Another indication for TACE before transplantation is in the context of "down-staging". If patients do not fulfill the transplantation criteria due to tumor size or extent, downstaging to a tumor burden within the criteria is possible. Furthermore, if down-staging is successful, patients generally 
have very good survival after LT, comparable to patients who were primarily within the criteria. ${ }^{129}$ Again, this emphasizes the high prognostic relevance of the response to tumor treatment.

\section{Future Perspectives}

Optimal selection becomes even more important in the light of the upcoming novel systemic therapies, first and foremost immunotherapy. The IMBRAVE 150 trial on patients with advanced stage HCC (BCLC C) has shown a major breakthrough in systemic therapies and may introduce the "golden twenties" for the treatment of nonresectable HCC. ${ }^{130}$ However, the number of emerging substances and experiences with systemic therapy may not only influence advanced stage disease. TACE for intermediate-stage HCC has been defined as the standard of care at a time when no systemic treatment was available. One limiting factor for successful locoregional treatment is often a high tumor burden. Immunotherapy as systemic treatment may be the better option for these patients while providing better tolerance than the available systemic options. However, no evidence has been created for the head-to-head comparison of TACE versus immunotherapy for patients in the intermediate stage yet. The first trial comparing the IMBRAVE150 combination Atezolizumab plus Bevacizumab with TACE, the ABC-HCC trial (NCT04803994), has not started patient recruitment yet. Thus, TACE will remain the primary treatment for the intermediate stage in the near future. Furthermore, the combination of TACE and immunotherapy is promising. Releasing tumor-associated antigens during TACE could stimulate the immune system, ideally leading to a synergistic effect. ${ }^{131}$ The major reason why the combination of TACE and tyrosine kinase inhibitors has failed repeatedly is unacceptable toxicity leading to early treatment termination. ${ }^{79-82}$ The lower rate of side effects and especially the lower liver toxicity of immunotherapy compared to tyrosine kinase inhibitors in the IMBRAVE 150 trial suggest that future combination of TACE and immunotherapy will be more tolerable. Several studies on this combination are currently recruiting (NCT04268888, NCT03572582, NCT03778957, and NCT04246177), with the most important one being the Phase 3 LEAP 012-trial. Overall, the eagerly awaited results of these trials will test our current staging and scoring systems and require new strategies to assign patients to one or a combination of both therapies.

\section{Summary}

TACE is the recommended treatment for intermediatestage HCC according to the BCLC classification. As this is a highly diverse subgroup, identifying patients who benefit from TACE remains crucial. Tumor-associated, patient-associated, and treatment-associated factors have to be considered when deciding whether to start TACE. However, interdisciplinary discussion is the basis for these individual decisions. During TACE treatment, patients should be monitored closely by cross-sectional imaging in order to precisely assess tumor response. TACE should be repeated as long as there is viable tumor in order to achieve optimal tumor control if no contraindications occur. In case of recurrence after CR, further TACE sessions and systemic treatment are feasible options. The decision between these two should be based on the extent of recurrence, the patient's liver function, and the performance status. Consequently, TACE should be stopped immediately in case of untreatable progression. In case of TACE refractoriness, a switch to systemic therapy should be made. Notably, a repeated interdisciplinary discussion of each case by the tumor board is of utmost importance for guiding patients through the treatment "jungle".

\section{Disclosure}

Lukas Müller and Fabian Stoehr are supported by the Clinician Scientist Fellowship "Else Kröner Research College: 2018_Kolleg.05”. Dr Roman Kloeckner reports personal fees from Boston Scientific, personal fees from Bristol-Myers Squibb, personal fees from Guerbet, personal fees from SIRTEX, personal fees from Roche, personal fees from EISAI, personal fees from Ipsen, personal fees from Siemens, personal fees from MSD - Merck Sharp \& Dohme, outside the submitted work. The authors report no other conflicts of interest in this work.

\section{References}

1. Galle PR, Forner A, Llovet JM, et al. EASL Clinical Practice Guidelines: management of hepatocellular carcinoma. J Hepatol. 2018;69(1):182-236. doi:10.1016/j.jhep.2018.03.019

2. Torre LA, Bray F, Siegel RL, Ferlay J, Lortet-tieulent J, Jemal A. Global Cancer Statistics, 2012. CA a Cancer J Clin. 2015;65 (2):87-108. doi:10.3322/caac. 21262

3. Heimbach JK, Kulik LM, Finn RS, et al. AASLD guidelines for the treatment of hepatocellular carcinoma. Hepatology. 2018;67 (1):358-380. doi:10.1002/hep.29086

4. Llovet JM, Brú C, Bruix J Prognosis of hepatocellular carcinoma: the BCLC staging classification. In: Seminars in Liver Disease. 19. Thieme Medical Publishers, Inc; 1999:329-338. 
5. Llovet JM, Real MI, Montaña X, et al. Arterial embolisation or chemoembolisation versus symptomatic treatment in patients with unresectable hepatocellular carcinoma: a randomised controlled trial. Lancet. 2002;359(9319):1734-1739. doi:10.1016/S01406736(02)08649-X

6. Lo CM, Ngan H, Tso WK, et al. Randomized controlled trial of transarterial Lipiodol chemoembolization for unresectable hepatocellular carcinoma. Hepatology. 2002;35(5):1164-1171. doi:10.1053/jhep.2002.33156

7. Bolondi L, Burroughs A, Dufour J-F, et al. Heterogeneity of patients with intermediate (BCLC B) Hepatocellular Carcinoma: proposal for a subclassification to facilitate treatment decisions. In: Seminars in Liver Disease. 32. Thieme Medical Publishers; 2012:348-359.

8. Weinmann A, Koch S, Sprinzl M, et al. Survival analysis of proposed BCLC-B subgroups in hepatocellular carcinoma patients. Liver Int. 2015;35(2):591-600. doi:10.1111/liv.12696

9. Adhoute X, Penaranda G, Naude S, et al. Retreatment with TACE: the ABCR SCORE, an aid to the decision-making process. J Hepatol. 2015;62(4):855-862. doi:10.1016/j.jhep.2014.11.014

10. Golfieri R, Giampalma E, Renzulli M, et al. Randomised controlled trial of doxorubicin-eluting beads vs conventional chemoembolisation for hepatocellular carcinoma. $\mathrm{Br} J$ Cancer. 2014;111(2):255-264. doi:10.1038/bjc.2014.199

11. Burrel M, Reig M, Forner A, et al. Survival of patients with hepatocellular carcinoma treated by transarterial chemoembolisation (TACE) using Drug Eluting Beads. Implications for clinical practice and trial design. $J$ Hepatol. 2012;56(6):1330-1335. doi:10.1016/j.jhep.2012.01.008

12. Malagari K, Pomoni M, Kelekis A, et al. Prospective Randomized Comparison of Chemoembolization with Doxorubicin-Eluting Beads and Bland Embolization with BeadBlock for Hepatocellular Carcinoma. Cardiovasc Intervent Radiol. 2010;33(3):541-551. doi:10.1007/s00270-009-9750-0

13. Herber SCA, Otto G, Schneider J, et al. Transarterial Chemoembolization in Patients Not Eligible for Liver Transplantation: single-Center Results. Am J Roentgenol. 2008;190(4):1035-1042. doi:10.2214/AJR.07.2755

14. Kirchhoff TD, Bleck JS, Dettmer A, et al. Transarterial chemoembolization using degradable starch microspheres and iodized oil in the treatment of advanced hepatocellular carcinoma: evaluation of tumor response, toxicity, and survival. Hepatobiliary Pancreat Dis Int. 2007;6(3):259-266.

15. Jun $\mathrm{CH}, \mathrm{Ki} \mathrm{HS}$, Lee $\mathrm{HK}$, et al. Clinical significance and risk factors of postembolization fever in patients with hepatocellular carcinoma. World J Gastroenterol. 2013;19(2):284-289. doi:10.3748/wjg.v19.i2.284

16. Degirmencioglu MA. Risk Factors for Postembolization Syndrome After Transcatheter Arterial Chemoembolization. Curr Med Imaging. 2019;15(4):380-385. doi:10.2174/ 1573405615666181122145330

17. Terzi E, Terenzi L, Venerandi L, et al. The ART score is not effective to select patients for transarterial chemoembolization retreatment in an Italian series. Dig Dis. 2014;32(6):711-716. doi:10.1159/000368007

18. Golfieri R, Cappelli A, Cucchetti A, et al. Efficacy of selective transarterial chemoembolization in inducing tumor necrosis in small $(<5 \mathrm{~cm})$ hepatocellular carcinomas. Hepatology. 2011;53 (5):1580-1589. doi:10.1002/hep. 24246

19. Blackburn H, West S. Management of postembolization syndrome following hepatic transarterial chemoembolization for primary or metastatic liver cancer. Cancer Nurs. 2016;39(5):E1E18. doi:10.1097/NCC.0000000000000302

20. Bruix J, Sala M, Llovet JM. Chemoembolization for hepatocellular carcinoma. Gastroenterology. 2004;127(5):S179-S188. doi:10.1053/j.gastro.2004.09.032
21. Chan AO, Yuen M-F, Hui C-K, Tso W-K, Lai C-L. A prospective study regarding the complications of transcatheter intraarterial lipiodol chemoembolization in patients with hepatocellular carcinoma. Cancer. 2002;94(6):1747-1752. doi:10.1002/ cncr. 10407

22. Kogut MJ, Chewning RH, Harris WP, Hippe DS, Padia SA. Postembolization syndrome after hepatic transarterial chemoembolization: effect of prophylactic steroids on postprocedure medication requirements. J Vasc Interv Radiol. 2013;24(3):326-331. doi:10.1016/j.jvir.2012.11.019

23. Kim BK, Shim JH, Kim SU, et al. Risk prediction for patients with hepatocellular carcinoma undergoing chemoembolization: development of a prediction model. Liver Int. 2016;36(1):92-99. doi:10.1111/liv.12865

24. Mazzaferro V, Llovet JM, Miceli R, et al. Predicting survival after liver transplantation in patients with hepatocellular carcinoma beyond the Milan criteria: a retrospective, exploratory analysis. Lancet Oncol. 2009;10(1):35-43. doi:10.1016/S1470-2045(08) 70284-5

25. Ebied OM, Federle MP, Carr BI, et al. Evaluation of responses to chemoembolization in patients with unresectable hepatocellular carcinoma. Cancer. 2003;97(4):1042-1050. doi:10.1002/cncr.11111

26. Benvegnu L, Noventa F, Bernardinello E, Pontisso P, Gatta A, Alberti A. Evidence for an association between the aetiology of cirrhosis and pattern of hepatocellular carcinoma development. Gut. 2001;48(1):110-115. doi:10.1136/gut.48.1.110

27. Kneuertz PJ, Demirjian A, Firoozmand A, et al. Diffuse infiltrative hepatocellular carcinoma: assessment of presentation, treatment, and outcomes. Ann Surg Oncol. 2012;19(9):2897-2907. doi: 10.1245/s10434-012-2336-0

28. Yang C-F, Ho Y-J. Transcatheter arterial chemoembolization for hepatocellular carcinoma. Cancer Chemother Pharmacol. 1992;31(1):S86-S88. doi:10.1007/BF00687113

29. Cho YK, Chung JW, Kim JK, et al. Comparison of 7 staging systems for patients with hepatocellular carcinoma undergoing transarterial chemoembolization. Cancer. 2008;112(2):352-361. doi:10.1002/cncr.23185

30. Savastano S, Miotto D, Casarrubea G, Teso S, Chiesura-Corona M. Transcatheter Arterial Chemoembolization for Hepatocellular Carcinoma in Patients With Child's Grade A or B Cirrhosis: a Multivariate Analysis of Prognostic Factors. $J$ Clin Gastroenterol. 1999;28(4):54. doi:10.1097/00004836199906000-00010

31. Lladó L, Virgili J, Figueras J, et al. A prognostic index of the survival of patients with unresectable hepatocellular carcinoma after transcatheter arterial chemoembolization. Cancer. 2000;88 (1):50-57. doi:10.1002/(SICI)1097-0142(20000101)88:1<50:: AID-CNCR8>3.0.CO;2-I

32. Doffoël M, Bonnetain F, Bouché O, et al. Multicentre randomised Phase III trial comparing Tamoxifen alone or with Transarterial Lipiodol Chemoembolisation for unresectable hepatocellular carcinoma in cirrhotic patients (Fédération Francophone de Cancérologie Digestive 9402). Eur J Cancer. 2008;44 (4):528-538. doi:10.1016/j.ejca.2008.01.004

33. Choi JW, Chung JW, Lee DH, et al. Portal hypertension is associated with poor outcome of transarterial chemoembolization in patients with hepatocellular carcinoma. Eur Radiol. 2018;28 (5):2184-2193. doi:10.1007/s00330-017-5145-9

34. Hucke F, Pinter M, Graziadei I, et al. How to STATE suitability and START transarterial chemoembolization in patients with intermediate stage hepatocellular carcinoma. J Hepatol. 2014;61 (6):1287-1296. doi:10.1016/j.jhep.2014.07.002

35. Sieghart W, Hucke F, Pinter M, et al. The ART of decision making: retreatment with transarterial chemoembolization in patients with hepatocellular carcinoma. Hepatology. 2013;57 (6):2261-2273. doi:10.1002/hep.26256 
36. Fatourou EM, Tsochatzis EA. ART and science in using transarterial chemoembolization for retreating patients with hepatocellular carcinoma. Hepatobiliary Surg Nutr. 2014;3(6):415. doi:10.3978/j.issn.2304-3881.2014.07.01

37. Kudo M, Arizumi T, Ueshima K. Assessment for retreatment (ART) score for repeated transarterial chemoembolization in patients with hepatocellular carcinoma. Hepatology. 2014;59 (6):2424-2425. doi:10.1002/hep.26760

38. Arizumi T, Ueshima K, Iwanishi M, et al. Evaluation of ART scores for repeated transarterial chemoembolization in Japanese patients with hepatocellular carcinoma. Oncology. 2015;89(Suppl. 2):4-10. doi:10.1159/000440625

39. Pinato DJ, Arizumi T, Jang JW, et al. Combined sequential use of HAP and ART scores to predict survival outcome and treatment failure following chemoembolization in hepatocellular carcinoma: a multi-center comparative study. Oncotarget. 2016;7(28):44705. doi:10.18632/oncotarget.9604

40. Yin W, Ye Q, Wang F, et al. ART score and hepatocellular carcinoma: an appraisal of its applicability. Clin Res Hepatol Gastroenterol. 2016;40(6):705-714. doi:10.1016/j. clinre.2016.05.005

41. Kloeckner R, Pitton MB, Dueber C, et al. Validation of clinical scoring systems ART and ABCR after transarterial chemoembolization of hepatocellular carcinoma. J Vasc Interv Radiol. 2017;28(1):94-102. doi:10.1016/j.jvir.2016.06.012

42. Mähringer-Kunz A, Kloeckner R, Pitton MB, et al. Validation of the Risk Prediction Models STATE-Score and START-Strategy to Guide TACE Treatment in Patients with Hepatocellular Carcinoma. Cardiovasc Intervent Radiol. 2017;40(7):1017-1025. doi:10.1007/s00270-017-1606-4

43. Johnson PJ, Berhane S, Kagebayashi C, et al. Assessment of liver function in patients with hepatocellular carcinoma: a new evidence-based approach - the ALBI grade. J Clin Oncol. 2015;33 (6):550. doi:10.1200/JCO.2014.57.9151

44. Pinato DJ, Sharma R, Allara E, et al. The ALBI grade provides objective hepatic reserve estimation across each BCLC stage of hepatocellular carcinoma. $J$ Hepatol. 2017;66(2):338-346. doi:10.1016/j.jhep.2016.09.008

45. Cappelli A, Cucchetti A, Cabibbo G, et al. Refining prognosis after trans-arterial chemo-embolization for hepatocellular carcinoma. Liver Int. 2016;36(5):729-736. doi:10.1111/liv.13029

46. Sposito C, Brunero F, Spreafico C, Mazzaferro V. External validation of an individual prognostic calculator after transarterial chemoembolization for hepatocellular carcinoma. Liver Int. 2016;8(36):1231. doi:10.1111/liv.13136

47. Garwood ER, Fidelman N, Hoch SE, Kerlan RK, Yao FY. Morbidity and mortality following transarterial liver chemoembolization in patients with hepatocellular carcinoma and synthetic hepatic dysfunction. Liver Transplant. 2013;19(2):164-173. doi:10.1002/1t.23552

48. Rekik S, Guyot E, Bhais M, et al. The CRP level and STATE score predict survival in cirrhotic patients with hepatocellular carcinoma treated by transarterial embolization. Dig Liver Dis. 2016;48(9):1088-1092. doi:10.1016/j.dld.2016.06.005

49. Di Martino V, Coutris C, Cervoni J, et al. Prognostic value of Creactive protein levels in patients with cirrhosis. Liver Transplant. 2015;21(6):753-760. doi:10.1002/lt.24088

50. Jun $\mathrm{CH}$, Ki HS, Lee $\mathrm{KH}$, et al. Impact of serum C-reactive protein level on the prognosis of patients with hepatocellular carcinoma undergoing TACE. Clin Mol Hepatol. 2013;19(1):70. doi:10.3350/cmh.2013.19.1.70

51. Kinoshita A, Onoda H, Imai N, et al. The addition of C-reactive protein to validated staging systems improves their prognostic ability in patients with hepatocellular carcinoma. Oncology. 2014;86(5-6):308-317. doi:10.1159/000360704
52. Czauderna C, Schmidtmann I, Koch S, et al. High pre-treatment static and dynamic alpha-fetoprotein values predict reduced overall survival in hepatocellular carcinoma. United Eur Gastroenterol J. 2020:2050640620972611. doi:10.1177/ 2050640620972611

53. Kadalayil L, Benini R, Pallan L, et al. A simple prognostic scoring system for patients receiving transarterial embolisation for hepatocellular cancer. Ann Oncol. 2013;24(10):2565-2570. doi:10.1093/annonc/mdt247

54. Park Y, Kim SU, Kim BK, et al. Addition of tumor multiplicity improves the prognostic performance of the hepatoma arterialembolization prognostic score. Liver Int. 2016;36(1):100-107. doi:10.1111/liv.12878

55. Galle PR, Foerster F, Kudo M, et al. Biology and significance of alpha-fetoprotein in hepatocellular carcinoma. Liver Int. 2019;39 (12):2214-2229. doi:10.1111/liv.14223

56. Cerban R, Ester C, Iacob S, et al. Predictive Factors of Tumor Recurrence and Survival in Patients with Hepatocellular Carcinoma treated with Transarterial Chemoembolization. J Gastrointest Liver Dis. 2018;27(4):409-417. doi:10.15403/ jgld.2014.1121.274.fcr

57. Takayasu K, Arii S, Kudo M, et al. Superselective transarterial chemoembolization for hepatocellular carcinoma. Validation of treatment algorithm proposed by Japanese guidelines. J Hepatol. 2012;56(4):886-892. doi:10.1016/j.jhep.2011.10.021

58. Zhu AX, Kang Y-K, Yen C-J, et al. Ramucirumab after sorafenib in patients with advanced hepatocellular carcinoma and increased $\alpha$-fetoprotein concentrations (REACH-2): a randomised, doubleblind, placebo-controlled, phase 3 trial. Lancet Oncol. 2019;20 (2):282-296. doi:10.1016/S1470-2045(18)30937-9

59. Melchiorre F, Patella F, Pescatori L, et al. DEB-TACE: a standard review. Futur Oncol. 2018;14(28):2969-2984. doi:10.2217/fon2018-0136

60. Lammer J, Malagari K, Vogl T, et al. Prospective Randomized Study of Doxorubicin-Eluting-Bead Embolization in the Treatment of Hepatocellular Carcinoma: results of the PRECISION V Study. Cardiovasc Intervent Radiol. 2010;33 (1):41-52. doi:10.1007/s00270-009-9711-7

61. Facciorusso A, Di Maso M, Muscatiello N. Drug-eluting beads versus conventional chemoembolization for the treatment of unresectable hepatocellular carcinoma: a meta-analysis. Dig Liver Dis. 2016;48(6):571-577. doi:10.1016/j.dld.2016.02.005

62. Erhardt A, Kolligs F, Dollinger M, et al. TACE plus sorafenib for the treatment of hepatocellular carcinoma: results of the multicenter, Phase II SOCRATES trial. Cancer Chemother Pharmacol. 2014;74(5):947-954. doi:10.1007/s00280-014-2568-8

63. Jin B, Wang D, Lewandowski RJ, et al. Chemoembolization Endpoints: effect on Survival Among Patients With Hepatocellular Carcinoma. Am J Roentgenol. 2011;196 (4):919-928. doi:10.2214/AJR.10.4770

64. Habbel VSA, Zeile M, Stavrou GA, et al. Correlation between SACE (Subjective Angiographic Chemoembolization Endpoint) score and tumor response and its impact on survival after DEB-TACE in patients with hepatocellular carcinoma. Abdom Radiol. 2019;44(10):3463-3479. doi:10.1007/s00261-019-02128-7

65. Llovet JM, Bruix J. Systematic review of randomized trials for unresectable hepatocellular carcinoma: chemoembolization improves survival. Hepatology. 2003;37:429. doi:10.1053/ jhep.2003.50047

66. Cammà C, Schepis F, Orlando A, et al. Transarterial Chemoembolization for Unresectable Hepatocellular Carcinoma: meta-Analysis of Randomized Controlled Trials. Radiology. 2002;224(1):47-54. doi:10.1148/radiol.2241011262

67. Oliveri RS, Wetterslev J, Gluud C. Transarterial (chemo)embolisation for unresectable hepatocellular carcinoma. Cochrane Database Syst Rev. 2011;1(3):544. doi:10.1002/14651858.CD004787.pub2 
68. Irie T, Kuramochi M, Takahashi N. Improved accumulation of lipiodol under balloon-occluded transarterial chemoembolization (B-TACE) for hepatocellular carcinoma: measurement of blood pressure at the embolized artery before and after balloon inflation. IVR. 2009;26:49-54.

69. Arai H, Abe T, Takayama H, et al. Safety and efficacy of balloonoccluded transcatheter arterial chemoembolization using miriplatin for hepatocellular carcinoma. Hepatol Res. 2015;45 (6):663-666. doi:10.1111/hepr.12403

70. Irie $T$, Kuramochi M, Kamoshida T, Takahashi N. Selective balloon-occluded transarterial chemoembolization for patients with one or two hepatocellular carcinoma nodules: retrospective comparison with conventional super-selective TACE. Hepatol Res. 2016;46(2):209-214. doi:10.1111/hepr.12564

71. Ogawa M, Takayasu K, Hirayama M, et al. Efficacy of a microballoon catheter in transarterial chemoembolization of hepatocellular carcinoma using miriplatin, a lipophilic anticancer drug: short-term results. Hepatol Res. 2016;46(3):E60-E69. doi:10.1111/hepr.12527

72. Liu B, Jiang C, Chen S, et al. Multipronged ethanol ablation combined with TACE for intermediate hepatocellular carcinoma. Minim Invasive Ther Allied Technol. 2018;27(5):300-308. doi:10.1080/13645706.2018.1427598

73. Yang B, Li C-L, Guo W, et al. Intra-arterial ethanol embolization augments response to TACE for treatment of $\mathrm{HCC}$ with portal venous tumor thrombus. BMC Cancer. 2018;18(1):1-10. doi:10.1186/s12885-018-3989-2

74. Kan Z, Wallace S. Transcatheter liver lobar ablation: an experimental trial in an animal model. Eur Radiol. 1997;7 (7):1071-1075. doi:10.1007/s003300050256

75. Li X, Feng GS, Zheng CS, Zhuo CK, Liu X. Expression of plasma vascular endothelial growth factor in patients with hepatocellular carcinoma and effect of transcatheter arterial chemoembolization therapy on plasma vascular endothelial growth factor level. World J Gastroenterol. 2004;10:2878. doi:10.3748/wjg.v10. i19.2878

76. Carmeliet P, Jain RK. Angiogenesis in cancer and other diseases. Nature. 2000;407(6801):249-257. doi:10.1038/35025220

77. Wang B, Xu H, Gao ZQ, Ning HF, Sun YQ, Cao GW. Increased expression of vascular endothelial growth factor in hepatocellular carcinoma after transcatheter arterial chemoembolization. Acta Radiol. 2008;49(5):523-529. doi:10.1080/02841850801958890

78. Kudo M, Imanaka K, Chida N, et al. Phase III study of sorafenib after transarterial chemoembolisation in Japanese and Korean patients with unresectable hepatocellular carcinoma. Eur J Cancer. 2011;47(14):2117-2127. doi:10.1016/j.ejca.2011.05.007

79. Lencioni R, Llovet JM, Han G, et al. Sorafenib or placebo plus TACE with doxorubicin-eluting beads for intermediate stage HCC: the SPACE trial. J Hepatol. 2016;64(5):1090-1098. doi:10.1016/j.jhep.2016.01.012

80. Meyer T, Fox R, Ma YT, et al. Sorafenib in combination with transarterial chemoembolisation in patients with unresectable hepatocellular carcinoma (TACE 2): a randomised placebo-controlled, double-blind, phase 3 trial. Lancet Gastroenterol Hepatol. 2017;2(8):565-575. doi:10.1016/S24681253(17)30156-5

81. Kudo M, Han G, Finn RS, et al. Brivanib as adjuvant therapy to transarterial chemoembolization in patients with hepatocellular carcinoma: a randomized phase III trial. Hepatology. 2014;60 (5):1697-1707. doi:10.1002/hep.27290

82. Kudo M, Cheng A-L, Park J-W, et al. Orantinib versus placebo combined with transcatheter arterial chemoembolisation in patients with unresectable hepatocellular carcinoma (ORIENTAL): a randomised, double-blind, placebo-controlled, multicentre, phase 3 study. Lancet Gastroenterol Hepatol. 2018;3(1):37-46. doi:10.1016/S2468-1253(17)30290-X
83. Kudo M, Arizumi T. Transarterial Chemoembolization in Combination with a Molecular Targeted Agent: lessons Learned from Negative Trials (Post-TACE, BRISK-TA, SPACE, ORIENTAL, and TACE-2). Oncology. 2017;93(Suppl. 1):127-134. doi:10.1159/000481243

84. Kudo M, Ueshima K, Ikeda M, et al. Randomised, multicentre prospective trial of transarterial chemoembolisation (TACE) plus sorafenib as compared with TACE alone in patients with hepatocellular carcinoma: TACTICS trial. Gut. 2020;69(8):1492-1501. doi:10.1136/gutjnl-2019-318934

85. Kudo M, Ueshima K, Ikeda M, et al. TACTICS: final overall survival (OS) data from a randomized, open label, multicenter, phase II trial of transcatheter arterial chemoembolization (TACE) therapy in combination with sorafenib as compared with TACE alone in patients (pts) with hepatocellular carcinoma (HCC). J Clin Oncol. 2021;39(3_suppl):270. doi:10.1200/ JCO.2021.39.3_suppl.270

86. Kloeckner R, Galle PR, Bruix J. Local and Regional Therapies for Hepatocellular Carcinoma. Hepatology. 2020;73 Suppl 1:137-149. doi:10.1002/hep.31424

87. Ronot M, Bouattour M, Wassermann J, et al. Alternative Response Criteria (Choi, European Association for the Study of the Liver, and Modified Response Evaluation Criteria in Solid Tumors [RECIST]) Versus RECIST 1.1 in Patients With Advanced Hepatocellular Carcinoma Treated With Sorafenib. Oncologist. 2014;19(4):394-402. doi:10.1634/theoncologist.2013-0114

88. Forner A, Ayuso C, Varela M, et al. Evaluation of tumor response after locoregional therapies in hepatocellular carcinoma. Cancer. 2009;115(3):616-623. doi:10.1002/cncr.24050

89. Shim JH, Lee HC, Kim S-O, et al. Which Response Criteria Best Help Predict Survival of Patients with Hepatocellular Carcinoma Following Chemoembolization? A Validation Study of Old and New Models. Radiology. 2012;262(2):708-718. doi:10.1148/ radiol.11110282

90. Lencioni R, Llovet JM Modified RECIST (mRECIST) assessment for hepatocellular carcinoma. In: Seminars in Liver Disease. 30. Thieme Medical Publishers; 2010 52-60.

91. Georgiades C, Geschwind J-F, Harrison N, et al. Lack of Response after Initial Chemoembolization for Hepatocellular Carcinoma: does It Predict Failure of Subsequent Treatment? Radiology. 2012;265(1):115-123. doi:10.1148/radiol.12112264

92. Kim SO. A Comparison of Lipiodol Chemoembolization and Conservative Treatment for Unresectable Hepatocellular Carcinoma. $N$ Engl $J$ Med. 1995;332(19):1256-1261. doi:10.1056/NEJM199505113321903

93. Miksad RA, Ogasawara S, Xia F, Fellous M, Piscaglia F. Liver function changes after transarterial chemoembolization in US hepatocellular carcinoma patients: the LiverT study. $B M C$ Cancer. 2019;19(1):795. doi:10.1186/s12885-019-5989-2

94. Dioguardi Burgio M, Sartoris R, Libotean C, et al. Lipiodol retention pattern after TACE for $\mathrm{HCC}$ is a predictor for local progression in lesions with complete response. Cancer Imaging. 2019;19(1):75. doi:10.1186/s40644-019-0260-2

95. Takayasu K, Arii S, Matsuo N, et al. Comparison of CT Findings with Resected Specimens After Chemoembolization with Iodized Oil for Hepatocellular Carcinoma. Am J Roentgenol. 2000;175 (3):699-704. doi:10.2214/ajr.175.3.1750699

96. Kloeckner R, Otto G, Biesterfeld S, et al. MRI Assessment of Tumor Response After Transarterial Chemoembolization for the Treatment of Hepatocellular Carcinoma. Cardiovasc Intervent Radiol. 2010;33(3):532-540. doi:10.1007/s00270-009-9728-y

97. Raoul J-L, Gilabert M, Piana G. How to define transarterial chemoembolization failure or refractoriness: a European perspective. Liver Cancer. 2014;3(2):119-124. doi:10.1159/ 000343867 
98. Galle PR, Tovoli F, Foerster F, Wörns MA, Cucchetti A, Bolondi $\mathrm{L}$. The treatment of intermediate stage tumours beyond TACE: from surgery to systemic therapy. J Hepatol. 2017;67 (1):173-183. doi:10.1016/j.jhep.2017.03.007

99. Kudo M, Paradigm A. Change in the Treatment Strategy for Hepatocellular Carcinoma. Liver Cancer. 2020;9(4):367-377. doi:10.1159/000507934

100. Peck-Radosavljevic M, Kudo M, Raoul J-L, et al. Outcomes of patients (pts) with hepatocellular carcinoma (HCC) treated with transarterial chemoembolization (TACE): global OPTIMIS final analysis. J Clin Oncol. 2018;36(15_suppl):4018. doi:10.1200/ JCO.2018.36.15_suppl.4018

101. Ogasawara S, Chiba T, Ooka Y, et al. Efficacy of Sorafenib in Intermediate-Stage Hepatocellular Carcinoma Patients Refractory to Transarterial Chemoembolization. Oncology. 2014;87 (6):330-341. doi:10.1159/000365993

102. Arizumi T, Ueshima $\mathrm{K}$, Chishina $\mathrm{H}$, et al. Validation of the Criteria of Transcatheter Arterial Chemoembolization Failure or Refractoriness in Patients with Advanced Hepatocellular Carcinoma Proposed by the LCSGJ. Oncology. 2014;87 (suppl1):32-36. doi:10.1159/000368143

103. Prince D, Liu K, Xu W, et al. Management of patients with intermediate stage hepatocellular carcinoma. Ther Adv Med Oncol. 2020;12:1758835920970840. doi:10.1177/1758835920970840

104. Torzilli G, Belghiti J, Kokudo N, et al. A Snapshot of the Effective Indications and Results of Surgery for Hepatocellular Carcinoma in Tertiary Referral Centers: is It Adherent to the EASL/AASLD Recommendations?: an Observational Study of the HCC East-West Study Group. Ann Surg. 2013;257 (5):929-937. doi:10.1097/SLA.0b013e31828329b8

105. Morimoto M, Numata K, Kondou M, Nozaki A, Morita S, Tanaka K. Midterm outcomes in patients with intermediate-sized hepatocellular carcinoma. Cancer. 2010;116 (23):5452-5460. doi:10.1002/cncr.25314

106. Yamakado K, Nakatsuka A, Takaki H, et al. Early-Stage Hepatocellular Carcinoma: radiofrequency Ablation Combined with Chemoembolization versus Hepatectomy. Radiology. 2008;247(1):260-266. doi:10.1148/radiol.2471070818

107. Hirooka M, Hiraoka A, Ochi H, et al. Transcatheter Arterial Chemoembolization With or Without Radiofrequency Ablation: outcomes in Patients With Barcelona Clinic Liver Cancer Stage B Hepatocellular Carcinoma. Am J Roentgenol. 2018;210 (4):891-898. doi:10.2214/AJR.17.18177

108. Xu Y, Shen Q, Liu P, et al. Microwave ablation for the treatment of hepatocellular carcinoma that met up-to-seven criteria: feasibility, local efficacy and long-term outcomes. Eur Radiol. 2017;27(9):3877-3887. doi:10.1007/s00330-017-4740-0

109. Riaz A, Gates VL, Atassi B, et al. Radiation Segmentectomy: a Novel Approach to Increase Safety and Efficacy of Radioembolization. Int J Radiat Oncol. 2011;79(1):163-171. doi:10.1016/j.ijrobp.2009.10.062

110. Vouche M, Habib A, Ward TJ, et al. Unresectable solitary hepatocellular carcinoma not amenable to radiofrequency ablation: multicenter radiology-pathology correlation and survival of radiation segmentectomy. Hepatology. 2014;60(1):192-201. doi:10.1002/hep. 27057

111. Wong TCL, Chiang C-L, Lee A-S, et al. Better survival after stereotactic body radiation therapy following transarterial chemoembolization in nonresectable hepatocellular carcinoma: a propensity score matched analysis. Surg Oncol. 2019;28:228-235. doi:10.1016/j.suronc.2019.01.006

112. Buckstein M, Kim E, Fischman A, et al. Stereotactic body radiation therapy following transarterial chemoembolization for unresectable hepatocellular carcinoma. J Gastrointest Oncol. 2018;9 (4):734-740
113. Kudo M, Ueshima $\mathrm{K}$, Chan $\mathrm{S}$, et al. Lenvatinib as an initial treatment in patients with intermediate-stage hepatocellular carcinoma beyond up-to-seven criteria and Child-Pugh a liver function: a proof-of-concept study. Cancers. 2019;11(8):1084. doi:10.3390/cancers 11081084

114. Arizumi T, Ueshima K, Minami $T$, et al. Effectiveness of Sorafenib in Patients with Transcatheter Arterial Chemoembolization (TACE) Refractory and Intermediate-Stage Hepatocellular Carcinoma. Liver Cancer. 2015;4(4):253-262. doi: $10.1159 / 000367743$

115. Wang Q, Xia D, Bai W, et al. Development of a prognostic score for recommended TACE candidates with hepatocellular carcinoma: a multicentre observational study. J Hepatol. 2019;70 (5):893-903. doi:10.1016/j.jhep.2019.01.013

116. Bourlière M, Pénaranda G, Adhoute X, Bronowicki J-P. The "sixand-twelve score" for TACE treatment: does it really help us? J Hepatol. 2019;71(5):1051-1052. doi:10.1016/j.jhep.2019.06.014

117. Zamparelli MS, Burrel M, Darnell A, et al. SAT503 - The "six-andtwelve" score in a prospective cohort of patients with hepatocellular carcinoma treated with trans-arterial chemoembolization following a fixed schedule. J Hepatol. 2020;73:S907. doi:10.1016/S01688278(20)32241-8

118. Han G, Berhane S, Toyoda H, et al. Prediction of survival among patients receiving transarterial chemoembolization for hepatocellular carcinoma: a response-based approach. Hepatology. 2020;72 (1):198-212. doi:10.1002/hep.31022

119. Mähringer-Kunz A, Weinmann A, Schmidtmann I, et al. Validation of the SNACOR clinical scoring system after transarterial chemoembolisation in patients with hepatocellular carcinoma. BMC Cancer. 2018;18(1):489. doi:10.1186/s12885018-4407-5

120. Facciorusso A, Bhoori S, Sposito C, Mazzaferro V. Repeated transarterial chemoembolization: an overfitting effort? $J \quad$ Hepatol. 2015;62(6):1440-1442. doi:10.1016/j. jhep.2015.01.033

121. Abajian A, Murali N, Savic LJ, et al. Predicting treatment response to intra-arterial therapies for hepatocellular carcinoma with the use of supervised machine learning - an artificial intelligence concept. J Vasc Interv Radiol. 2018;29(6):850-857. doi:10.1016/j.jvir.2018.01.769

122. Peng J, Kang S, Ning Z, et al. Residual convolutional neural network for predicting response of transarterial chemoembolization in hepatocellular carcinoma from CT imaging. Eur Radiol. 2020;30(1):413-424. doi:10.1007/s00330-019-06318-1

123. Mähringer-Kunz A, Wagner F, Hahn F, et al. Predicting survival after transarterial chemoembolization for hepatocellular carcinoma using a neural network: a Pilot Study. Liver Int. 2020;40 (3):694-703. doi:10.1111/liv.14380

124. Liu D, Liu F, Xie X, et al. Accurate prediction of responses to transarterial chemoembolization for patients with hepatocellular carcinoma by using artificial intelligence in contrast-enhanced ultrasound. Eur Radiol. 2020;30(4):2365-2376. doi:10.1007/ s00330-019-06553-6

125. Forner A, Reig M, Bruix J. Hepatocellular carcinoma. Lancet. 2018;391(10127):1301-1314. doi:10.1016/S0140-6736(18) 30010-2

126. Mazzaferro V, Regalia E, Doci R, et al. Liver transplantation for the treatment of small hepatocellular carcinomas in patients with cirrhosis. $N$ Engl J Med. 1996;334(11):693-700. doi:10.1056/ NEJM199603143341104

127. Sandow T, Pavlus J, Field D, et al. Bridging hepatocellular carcinoma to transplant: transarterial chemoembolization response, tumor biology, and recurrence after transplantation in a 12-year transplant cohort. J Vasc Interv Radiol. 2019;30 (7):995-1003. doi:10.1016/j.jvir.2018.12.736 
128. Otto G, Schuchmann M, Hoppe-Lotichius M, et al. How to decide about liver transplantation in patients with hepatocellular carcinoma: size and number of lesions or response to TACE? J Hepatol. 2013;59(2):279-284. doi:10.1016/j.jhep.2013.04.006

129. Yao FY, Mehta N, Flemming J, et al. Downstaging of hepatocellular cancer before liver transplant: long-term outcome compared to tumors within Milan criteria. Hepatology. 2015;61 (6):1968-1977. doi:10.1002/hep.27752
130. Finn RS, Qin S, Ikeda M, et al. Atezolizumab plus Bevacizumab in Unresectable Hepatocellular Carcinoma. $N$ Engl J Med. 2020;382(20):1894-1905. doi:10.1056/NEJMoa1915745

131. Duffy AG, Ulahannan SV, Makorova-Rusher O, et al. Tremelimumab in combination with ablation in patients with advanced hepatocellular carcinoma. $J$ Hepatol. 2017;66 (3):545-551. doi:10.1016/j.jhep.2016.10.029

\section{Publish your work in this journal}

The Journal of Hepatocellular Carcinoma is an international, peerreviewed, open access journal that offers a platform for the dissemination and study of clinical, translational and basic research findings in this rapidly developing field. Development in areas including, but not limited to, epidemiology, vaccination, hepatitis therapy, pathology and molecular tumor classification and prognostication are all considered for publication. The manuscript management system is completely online and includes a very quick and fair peer-review system, which is all easy to use. Visit http://www.dovepress.com/ testimonials.php to read real quotes from published authors.

Submit your manuscript here: https://www.dovepress.com/journal-of-hepatocellular-carcinoma-journal 